\title{
Effect of exercise training before mating on mRNA expression of breast cancer-related genes in offspring in rats
}

\section{[Effet de l'entraînement physique avant l'accouplement sur l'expression de l'ARNm de gènes liés au cancer du sein chez la progéniture du rat]}

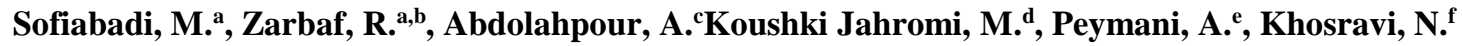 \\ ${ }^{a}$ Cellular and molecular Research Center, Research Institute for prevention of Non-communicable Disease, \\ Qazvin University of Medical Sciences, Qazvin, Iran \\ ${ }^{b}$ Department of sport sciences, school of socialize science, Imam Khomeini international university, Qazvin, Iran \\ 'Department of sport sciences, Faculty member of Qazvin Islamic Azad University, Qazvin, Iran \\ Corresponding author: Zarbaf, R.; Cellular and molecular Research Center, Research Institute for prevention of \\ Non-communicable Disease, Qazvin University of Medical Sciences, Qazvin, Iran; \\ email:reyhaneh64white@gmail.com
}

\begin{abstract}
Purpose: Exercise is associated with reduced risk of breast cancer, however, effect of parental exercise on risk of breast cancer in children has not been studied. Thus, the aim of the present study was evaluating the effect of aerobic training of parents before pregnancy on the expression of some of the main genes in breast cancer in breast tissue of their offspring. Method: Eighteen female and 6 male Sprague Dawley rats were randomly divided into two exercise training and control group. After training each male mated with 2 females. Parental aerobic training with moderate intensity was performed running on treadmill for 4 weeks, 5 sessions per week. Finally Pairs 4, 5, and 6 of adult breast tissues was performed to evaluate the expression of BRCA1, TP53, ER- $\alpha$, IGF-1 and IGF-1R. Results: We found that prepregnancy moderate aerobic training of mother, especially along with father caused a significant increase in the mRNA of the BRCA1, P53 and ER- $\alpha$ genes, and a significant reduction in IGF-1 and IGF-1R. Conclusion: Exercise with moderate intensity before mating significantly affected the expression of BRCA1, P53, IGF-1, IGF-1R and ER- $\alpha$ genes. So we suggest that parents regular exercise before pregnancy can reduce the risk of breast cancer in children.
\end{abstract}

Keywords: Pre-pregnancy Aerobic Activity, BRCA1, P53, Rat 